\title{
XII. Memoir upon the desulphuration of metals
}

\section{Gueniveau}

To cite this article: M. Gueniveau (1808) XII. Memoir upon the desulphuration of metals , Philosophical Magazine Series 1, 32:125, 78-86, DOI: $10.1080 / 14786440808562762$

To link to this article: http://dx.doi.org/10.1080/14786440808562762

$$
\text { 册 Published online: } 18 \text { May } 2009 .
$$

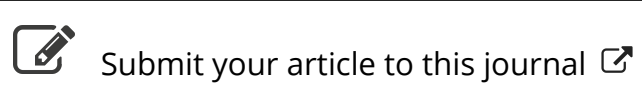

\footnotetext{
Џ Article views: 2
}

Q View related articles $\sqsubset$ 
Scotland, Ireland, and northern parts of England. It is an animal, when tamed, very familiar, and will eat bread and milk, willow-sticks, elm, bark, \&cc., and no doubt might be imported with safety; but as these two last-mentioned animals are not likely to be at tended to immediately, I shall say no more respecting them for the present.

,Pine Timber. There are many thousand of large pine trees on the burders of the lakes, rivers, \&c. in Upper Canada, which might be marked and secured for naval purposes, and which might be floated down to Montreal and Quebec with great ease, and which no doubt would be of great benefit in furnishing a large supply of good masts for the navy of this empire.

\section{Memoir upon the Desulphuration of Metals. By M. Greniveau, Engineer to the Mines.}

[Concluded from vol. xxxi. p. 213.]

\section{Roasting of Galena.}

$I_{T}$ is extremely difficult completely to desulphurate galena by roasting: the affinity of its component parts for oxygen does indeed effect their disunion quickly enough; but that of the new compounds, the sulphuric acid and the oxide of lead, gives birth to a new combination, which retains the sulphur, and thus forms an obstacle to the desulphuration: to this same affinity of the oxide of lead for the sulphuric acid, we must attribute the facility with which this acid is formed in the roasting of galena.

I shall examine in detail the various processes to which this important decomposition gives rise, as I think they will explain numerous and complex phænomena.

Whatever care is taken in roasting galena, it is impossible to convert all the sulphur into sulphurous acid, and to avoid the formation of sulphuric acid; the result always gives a mixture of oxide and of sulphate of lead.

In roastings performed upon a large scale, and in a regtilated atmosphere, the proportion of sulphate of lead is much 
more considerabie, it is regulated by the temperature and by the facility with which the air penetrates the ore; numerous experiments made in l'Ecole des Mines incline me to think that the roasted schlich of the Pezey ore contait $s$ half its weight of sulphate of lead; whence it follows, that even supposing the whole galena to be decomposed, the roasting has not separated the half of the sulphur it contains.

The reverberating furnace may be employed with great success in roasting the sulphurized ores of lead. In some foundries, they produce in this kind of furnace so complete a separation of the sulphur, that it is sufficient, when the roasting is supposed to be finished, to add some charcoal, in order to obtain instantaneously a great quantity of metallic lead. Il cannot be doubted, however, that a great quantity of sulphate of lead is formed; which, as we have already seen, is a necessary result of the action of the air upon galena exposed to a high temperature; the chimneys of the furnaces are likewise filled with the above substance: the decomposition of this sulphate by charcoal produces a sul. phuret or a matte of lead; and although sulphurous acid may be disengaged, it is very difficult to explain why the addition of charcoal makes the lead flow instantly in a considerable quantity. I thought that the sulphate of lead was decomposed during the roasting, and that nothing remained after this operation, but an oxide a little mixed; and I thought I discovered the cause of this decomposition in the action of the galena, as yet undecomposed, upon the sulphate formed. The following experiments will show the nature and result of this action.

I put into a retort a mixture composed of one part of pulverized sulphuret of lead, and three of sulphate*, and I heated it at first but slowly. When the retort was red-hot, a considerable disengagement of sulphurous acid gas took place which lasted an hour, when the retort melled; the residue presented a mixture of oxide and of sulphate of lead. I ascertained that the su!phurous acid which had been collected in the water was not mixed with sulphuric acid.

* This mixture was made in the humaid way. 
This experiment demonstrates in an indisputable manner the decomposition of the sulphate of lead by the sulphuret, or rather that of the sulphuric acid which it contains, by the sulphur and the lead of the galena. The sulphurous acid certainly proceed 3 both from the oxygenation of the sulphur, and from the demi-decomposition of the acid, as I am convinced that no sulphate remained in the residue. I repeated this decomposition, employing equal parts of galena and of sulphate; the sulphurous acid disengaged was more abundant, and there remained in the retort a mixture of oxide and of sulphuret; from which I concluded, that if, in the first experiment, the proportion of sulphuret of lead was too weak, it was too strong in the latter. I also made another attempt to attain some proportions rigorously sufficient for the mutual decomposition, and endeavoured at the same time to assure myself of the oxidation of the lead contained in the galena in a metallic state. I put fourteen grammes of sulphate, well mixed with eight grammes of sulphuret, in a crucible, which I allowed to become red-hot in a gradual manner. I remarked that a considerable crackling was produced, occasioned by the disengagement of the sulphurous acid. I did not take the crucible from the fire until I saw its contents melted. I found two substances well separated; the one occupying the bottom of the crucible was merely melted sulphuret of lead, without any mixture of ductile lead; the other presented all the characters of the oxide of lead called glass of lead; this part was a combination of oxide and of silex, proceeding from the materials of the crucible, without any marks of sulphate of lead.

This experiment proved that the lead of the galena was oxidated at the expense of the sulphuric acid; but it did not show the quantity of galena necessary to the complete decomposition of the sulphate. I am of opinion, however, that the proportion of one part of the former to two of the latter is sufficient; besides, it closely resembles the proportion which calculation gives us of the composition of these substances.

The following are the natural consequences of these facts: 1st. The galena and the sulphate of lead are mutually de- 
composed at a high temperature. 2d. This decomposition gives place to the formation and to the disengagement of a great quantity of sulphurous acid, and consequently to the separation of a considerable portion of the sulphur contained in the ore*. 3d. The result is oxide of lead, when the proportions are proper; and in the contrary case a mixture of oxide and of sulphat, or oxide and galena. The application of these consequences to the roasting of the sulphuret of lead in this reverberating furnace is very easy. I shall explain the theory of this operation in the way I conceive it.

The pulverized galena, or the schlich of lead, spread out upon the floor of the furnace in a layer of a few inches in thickness, the upper part of which is exposed to the action, produces the phænomena usually observed in the common roastings. The heat vaporises a little sulphur; the air converts that part upon which it acts into sulphurous acid, which is liberated; but a much greater part is converted into sulphuric acid, which is combined with the lead oxidized at the same time. The ores are stirred; the sulphate of lead is mixed with the undecomposed schlich, and their decomposition produces sulphurous acid; the surface of the layer which has been renewed, reproduces sulphate, which afterwards serves to produce a new disengagement of gas, and thus continues the desulphuration, to which we find there is no end except the complete decomposition of the galena. If the operation has been well managed; and if too much sulphate of lead has not been formed, the result of the roasting will be almost pure oxide of lead; in the contrary case, some sulphate will probably remain, which charcoal will bring back to the state of sulphuret, and the decomposition of which will take place like that of the galena. We may judge from this detail, how important it is to avoid melting the sulphuret of lead subjected to roasting; for the action of the air upon the melted ore will soon be rendered null by

* If we admit that a mixture of one part of sulphuret and two of sulphate are entirely decomposed and reduced to oxide of lead, the quantity of sulphur separated will be two-fifths: so that one part of sulphate, in an indefinite quantity of galena, will separate one-fifth of sulphur; aud one of sulphuret in sulphate will separate three-fifths.

Vol, 32. No. 125. Oct. 1808. 
the formation of the oxide of lead which will cover it ; and the sulphate of lead not being capable of being any longer mixed with the galena, there will be no method left of desulphuration.

The roasting of galena in the reverberating furnace is therefore reduced to the conversion of the sulphur which it contains into sulphutrous acid; and as it is produced in a great measurc by the intermedium of the sulphate of lead which is continually formed, this process admits of a much more complete desulphuration than the others.

The same decomposition of the sulphuret of lead by the sulphate, in my opinion, takes place also in the treatment of the ores of lead in what are called Scotch furnaces : in Scotland they roast and melt galena by one uninterrupted operation, employing coal and turf.

This kind of furnace is employed with success in the mine at Pezey, in melting roasted galena containing at least $\frac{1}{y}$ of its weight of sulphate of lead. It gives no mattes as a final result, which proves that it admits of the decomposition of the sulphate and the separation of the sulphur contained in it. I am of opinion that the action of the portion reduced to the state of sulphuret by the contact of the coals upon the undecomposcd sulphate, is one of the principal causes of the desulphuration produced.

We have had occasion to speak of several kinds of furnaces, (the Fahlun and Scotch furnaces among the rest, in which the metallic sulphurets will undergo a real roasting 5 but there are others where this effect is scarcely perceptible. I consider the present as a proper opportunity for introducing some reflections upon the differences they exhibit in this respect. They ought to excite the more interest, because they are intimately connected with the present subject, and explain some phænomena which cannot be accounted for from the way in which the operation of roasting has generally been regarded.

It is a well-known fact, in foundries, that the highest furnaces are those which admit of desulphuration the least, or, in the language of the workmen, they produce the most matles. If a convincing proof of this is wanted, it will be sufficient 
sufficient to mention, that at Pezey there have been seen roasted ores of lead, containing a great deal of sulphate of lead, the flux of which, in the Scutch furnace, gave no mattes, and yet they produce a great quantity when they are passed to the common furnace.

If heat alone decomposes easily and completely the me tallic sulphurets, the upper part of the high furnaces wil. be very proper for operating the roasting of ores; for besides the temperature being a little elevated, the air which ascends to that height, being deprived of a part of its oxygen, forms very little more of these sulphates which are opposed to the separation of the sulphur: but it is quite different, and in my eyes it is a new proof of the little effect of the action of caloric alone upon substances. The sulphur is separated from the sulphurets, as we have seen, in the state of sulphurous acid, and oxygen is indispensable to its formation. In furnaces not much raised, the air which touches the ore recently thrown in, still contains a great deal of oxygen; the sulphurous acid formed is soon subjected to the deoxidating action of the coals; if there be a small portion of it decomposed, a new sulphuret is formed, which is afterwards roasted like the mineral. In the Scotch furnace, for example, when mattes are melted, they are thrown successively into the furnace, and what has escaped one operation is decomposed by a second. In high furnaces, on the contrary, the ores placed in the upper part undergo but a very imperfect desulphuration, because the air which comes in contact with it contains but very litule free oxygen, the sulphurous acid formed in the interior is in a great measure decomposed by traversing the whole height of the furnace filled with coals, and the sulphuret is recomposed; the latter tends by its gravity to gain the basin, where it does not arrive until after a series of decompositions, which cannot take place, as we have in fact observed, without there resulting a considerable loss in metal.

All these facts seem to leave no doubt as to the following proposition: The decomposition of the metallic sulphurets by roasting is produced by the oxygenation of its compounds, 
and the sulphur is separated more or less completely in the state of sulphurous acid.

\section{\$III. Desulphutration of the Metals independent of the Action of the Air.}

The varied affinities of sulphur for different mineral substances, furnish the means of decomposing certain sulphurets; and several have been employed in metallurgy with success. In order that the decomposition of a metallic sulphuret by any mineral should form the basis of a metallurgic process, it is not sufficient that the affinity of this mineral for sulphur should be greater than that of the metal; it must, besides the conditions required by œconomy, also possess several other requisites absolutely necessary for the success of the operation, which considerably limit the number of the agents pointed out by chemistry : for instance, if the sulphuret resulting from the decomposition is not fusible, or but very little so, if it has the property of combining with the metal required to be separated, or rather with the still undecomposed sulphuret, it is evident that we cannot effect our purpose, namely, the isolation of the metallic substance. Hitherto little else has been used except bime and $i r o n$.

Desulpharation of Mercury.-It is very exsy to decompose the sulphuret of mercury; it being sufficient if we present to the sulphur a substance capable of retaining it, and volatilize the mercury alone. It is thus that iron and lime are employed together or separately in the treatment of the ores of cinnabar.

Desulphuration of Copper.- Pyritous copper is melred in some foundries with lime, either in the common or in the reverbersting furnace; but the process is not well enough known as yet to enable us to judge of the efficacy of lime as an agent in this case.

I was once of opinion, with some metallurgists, that the well-known superior affinity of iron for sulphur over that of copper for the same combustible, might determine the decomposition of the sulphuret of copper by this metal, at least 
in certain cases. The following experiments, however, did not warrant me in continuing of this opinion.

First Experiment.-I made a mixture of ten grammes of pyritous copper, the composition of which $\lfloor$ knew, with four grammes of iron filings: I put this into a crucible, covered with charcoal in powder, and heated it in the forge for three quarters of an hour. The proportion of the iron bad been calculated so accurately that it was sufficient for taking up all the sulphur combined with the copper in the mineral employed. I found in the crucible a perfectly homogeneous mass, weighing thirteen grammes, which did not contain the smallest globule of metallic copper, nor any appearance of stparation, between the sulphuret of iron and that of copper *.

Second Experiment. - Another trial was made by employing ten grammes of pyritous copper and five grammes of the same roasted mineral. This is nearly the case with the fluxes in which the ore or the mattes are not completcly desulpburated; the proportion of the iron was still sufficient for separating copper, which was very abundant in the mixture. I kept up the heat. for three quarters of an hour, and found, as in the preceding experiment, a homogeneous mass, without any trace of metallic copper, nor of pure sulphuret of copper; this was a real matte of copper.

Third Experiment.-On this occasion an equal mixture of crude pyritous copper, and roasted copper, dipped in olive oil, and heated strongly for half an hour in a crucible, presented nothing but a powder, which had not undergone fusion, on account, without doubt, of the superabundance of the iron.

I think these few experiments are sufficient for proving that the desulpharation of copper by means of iron will be always very difficult, because there is formed a triple combination letween the sulphur, iron and copper, or rather a combination between the sulphurets of copper and of iron, which prevents the separation of the copper.

* In the decomposition of galena by iron, we observe, when the latter is in too small quantity, three distinct substances of lead, sulphuret of lead, and lastly, sulphuret of iron in the upper part. 
Dcsulphuration of Galena. - This is one of the sulphurets which best yields to the decomposition in question; the fusibiiity of the lead which facilitates its aggregation, as well as the little affinity it has for sulphur, are the causes of the successtul trials that have been made on this subject. Lime and iron are employed in various circumstances in the desulphuation of galena; the use of lime is not very general, and it is impossible to judge of its effects from what is known of the properties of the sulphuret of lime. The treatment of galena by iron is more in use, and appears more advantageous.

The above memoir will, I hope, suggest several experiments to those who are engaged in metallurgical pursuits.

All the experiments I have detailed were performed in the laboratory belonging to the Council of the Mines, and under the eyes of M. Descostils, by whose superior judgement I profited considerably during the progress of my labours.

XIII. Report of Surgical Cases in the City and Finslury Dispensaries, for April, May, and $J_{\text {une, }} 1$ \&08. With two Cases of Dropsy of the Ovarium. By John Taunton, Esq.

$\mathrm{I}_{\mathrm{N}}$ April, May, and June, there were admitted on the books of the City and Finsbury Dispensaries 785 surgical patients.

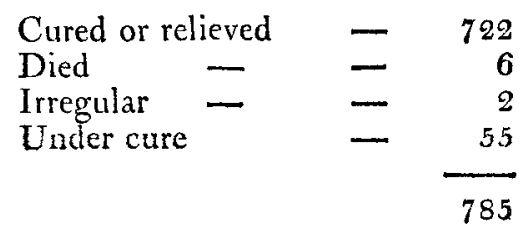

Mrs. Dennison, ætat. 29, has generally enjoyed a good state of health till within about eighteen months, when she had symptoms of dropsy of the ovarium; the right side of the abdomen enlarged most, was irregular, and has been most painful during the continuance of the disease.

The catamenia stopped about a year since, when the abdo- 